\title{
PROEVE EENER beREKENING VAN de KoOpWAaRde VAN DEN NEOERLANDSCHEN BODEM BIJ DEN LANDBOUW IN GEBRUIK.
}

Het is zeker een moeielijk te beantwoorden vraag ,hoeveel de waarde van den Nederlandschen bodem, bijj den landbouw in gebruik," bedraagt.

Vele oorzaken toch dragen er toe bij, dat hier voor den grond een goedkoope, elders weder voor dezelfde soort een zeer hooge prijs bedongen wordt.

In gemeenten, die door nangename of gezonde ligging bewoners tot zich trekken, waar villa bij villa verrijst, kan men zelfs voor zeer schralen zandgrond een hoogeren prijs vorderen dan elders voor den vruchtbaarsten kleibodem.

In den omtrek onzer groote steden, die zich tegenwoordig door aanbouw bijna alle uitbreiden, worden zelfs fabelachtige prijzen voor den bodem betaald. De behoefte die in de dichtbevolkte gemeenten bestaat aan versche groenten en melk, is oorzaak dat zelfs op betrekkelijk verren afstand van deze centra, prijzen voor het bouw- en grasland te bedingen zijn, die elders nergens besteed kunnen worden, hetgeen zich in Noord- en Zuidholland b.v. sterk en in zekere mate nog in Utrecht doet gevoelen. Sommige cultures aan eene bepaalde streek eigen, zijn mede van grooten invloed op den prijs der gronden.

Goed tabaksland b.v. wordt veel duurder verkocht dan andere daar in den omtrek gelegen perceelen. Een goede hyacyntenbodem wordt voor $f 10.000$ tot $f 12.000$ en meer per HA. verkocht; voor een Westlandschen tuin wordt meermalen een bijna even hooge prijs bedongen.

Voor tuin en warmoezenijgronden betaalt men algemeen veel meer dan voor bouw- of grasland.

Doch ook de ligging van de perceelen heeft invloed op den prijs, zonder dat wij hier de nabijheid van steden of op de bijzon- 
dere cultures dic in den omtrek worden gedreven, op hot oog hebben.

In streken die met waterwegen doorsneden zijn, waar alzoo op goolkoope wijze mest kan worden aan- en de producten kunnen worlen afgevoerd, zal men hoogeren prijs voor den grond besteden dan daar, waar wel cen even vruchtbare bodem aanwezig is, doch vaarten en kanalen ontbreken. Goede laudwegen oefenen eveneens denzelffen invloed uit, hoezcer in mindere mate dan kanalen. Ook de totstandkoming ran kunst-spoor- en tramwegen hebben veelal cen verhooging ran de warrde van den bodem in den omtrek der stations tengevolge, meestal met het oog op speculatie.

Gronden zooals in de Butuwo, omsloten rloor Rijn en Waal, en in Limburg en Noord-Brabant langs de: Maas, gronden dus, die telken jare gevaar kunnen loopen overstroomal to worden, hebben door deze risico een geringere waarde dan een even viuchtbare horlem, welke niet, of althans minder an dit gevaar onderhevig is.

De uiterwaarden langs unze groute rivieren bedingen wel is waar als grasland nog steeds cen Hinken prijs, doch de prijs wordt veel hooger, wameer liort in den omtrok steenfabrioken verrijzen.

Zware polderlasten, zooals vrij algemeen in Zeeland, of beklentrechten met geschenken als in Groningen, zijn tevens van grooten invloed op den koopprijs, en zijn oorzaak, dat die prijs schijnbaar ver blijft beneden die van gronden, welke inderdaad veel minder vruchtbaar zijn.

Wij zouder nog meer verschillende oorzaken kunuen aanwijzen, die op den koopprijs van den bodem van onmiskenbaren invloed zijn, maar laten het hierbij, daar het door ons aangehaalde voldoende is om te doen zien, welke moeielijkheden er aan verbonden zijn, om met eenige zekerheid de waarde van den Nederlandschen bodem bij den landbouw in gebruik te berekenen. Onmogelijk is dit laatste zeker, wanneer meu niet over een groot aantal vertrouwbare gegevens beschikken kan, en ook wanneer gevorderd wordt dat de berekening op een paar millioenen na, nauwkeuriy. moet zijn. Doch ook al beschikt men over vele gegevens, dan moet uit deze hoeveelheid vertrouwbare bronnen nog met omzichtigheid eene keus gedaan worden.

In de eerste plaats moeten deze gegevens gerangschik worden naar den aard van den bodem, waarop zij betrekking hebben.

De gegevens, die doelen op gemeenten op kleigrond, moeten 
gescheiden worden van die, welke gemeenton betreffon op zandof veengrond gelegen, terwijl ook deze twee laatste grondsoorten niet met elkander verward mogen worden.

Doch ook hier stuit men weder op moeielijkheden. Vooreerst zijn er vele gemeenten, die zoowel op zand-, veen- als kleigrond gelegen zijn. Bezit men nu van een dergelijke gemeente slechts écn gegeren, dan mag daarnaar in geen geval de prijs van den bodem der geheele gemeente berekend worden.

Om nu bij de berekening te voorkomen, dat door gemeenten, die zoowel op klei-, zand- en veengrond gelegen zijn, een over het geheel noemenswaardige fout ontstaan zou, hebben wij voor de waardeberekening landbouwstelsels aangenomen, en wel die, waaronder $\mathrm{dr}$. Staring de verschillende gemeenten in ons land heeft gerangschikt, zoodat de fout, die aan de eene zijde wordt gemaakt, door een ander wordt opgeheven of althans voor het grootste deel wordt geneutraliseerd.

Deze bovenbedoelde stelsels zịjn de navolgende:

1. Zandgronden.

Drieslagstelsel.

Twentsche roggebouw.

Vlaamsche bouwerij.

Geestbouwerij.

2. Veengronden (hoog- en laag veen).

Rijenteelt (afgeveend hoog veen).

Veehouderij (grasland, laag veen).

3. Kleigronden.

Korenbouwerij.

Tarweteelt.

Polderbouw.

Veehouderij (grasland).

Nu komt het wel is waar voor, dat er gemeenten zijn, die onder het Drieslagstelsel gerangschikt zijn, doch waaronder ook een groote uitgestrektheid kleigrond aanwezig is. Van den anderen kant zijn er evenwel, die onder een der stelsels „korenbouwerij" of "tarweteelt" zijn ingedoeld, doch die voor een groot deel zandgrond onder haar gebied aanwijzen. Zoodoende wordt de fout, zooals we hiervoren reeds opmerkten, die men voor de eene gemeente begaat, door een ander gecompenseerd.

Het eenige wat ex ter berekening als nu te doen overblijft, is naar bepaalde typen te zoeken voor elk stelsel en voor elke gemeente afzonderlijk, welke typen dan ook met eenig goed oordeel 
niet zeer moeielịk te vinden zịn. Men dient echter vooral te letten op de grootte der verkochte perceolen. Kleine oppervlakten gronds brengen meestal to hooge prijzen op, om als matstaf te mogen gelden. Hier zịn dergelijke kleine perceelen voor bijzondere doeleinden bijzonder geschikt, elders weder zijn zij door ligging een servituut voor een of meer anilere perceelen, waardoor zij voor de bezitters van laatstgenoemde objecten een hongere waarde vorkrijgen, dan werkelijk in den bodem huisvest.

Op alle deze omstandigheden is door ons bij de berekening van de waarde van den bij den landbouw in gebruik zijnde hodem gelet, en hebben wij uit de ruim 3400 vertrouwbare opgaven, die over de drie laatste jaren ter onzer heschikking waren - ook uit het Verslag over den Landbouw 1881 en 1882 - die opgaven gekozen, welke betrekking hadden op perceelen van minstens 6 HA. Daaronder komen zoowel behuisde als niet behuisde perceelen voor.

Uit die verschillende opgaven bleek verder, dat vrij algemeen de prijs van het grasland hooger is dan van het bouwland. Waar alzoo over voldoende gegevens beschikt kon worden, hebben wij zoowel voor het bouw- als voor het grasland den gemiddelden koopprijs berekend.

Waren die opgaven in niet voldoende mate voorhanden, dan moest natuurlijk de prijs van beiden gelijk worden gesteld, en zeer zeker is daardoor een fout gemaakt, die evenwel, over de betrekkelijk kleine oppervlakten waarvoor dit noodzakelijk was, niet belangrijk kan zijn. Met inachtneming van deze versehillende omstandigheden zijn wij tot de navolgende berekeningen gekomen.

Vooreerst is nu hier in tabel I de waarde berekend van het bouw- en grasland van elk stelsel in de onderscheiden provinciën. 


\begin{tabular}{|c|c|c|c|c|c|c|c|c|}
\hline \multirow{2}{*}{$\begin{array}{c}\text { I. } \\
\text { LANDBOWW- } \\
\text { STRLISELS. }\end{array}$} & \multirow[t]{2}{*}{ Provinctre. } & \multicolumn{2}{|c|}{$\begin{array}{l}\text { Gemiddelde } \\
\text { prijs per HA. } \\
\text { in guldens van }\end{array}$} & \multicolumn{2}{|c|}{ Aantal HA. } & \multicolumn{3}{|c|}{$\begin{array}{c}\text { Totral waarde (in duizendtallen } \\
\text { guldens) ran het }\end{array}$} \\
\hline & & $\begin{array}{l}\text { Bouw- } \\
\text { land. }\end{array}$ & $\begin{array}{l}\text { Gras- } \\
\text { land. }\end{array}$ & $\begin{array}{l}\text { Bouw- } \\
\text { land. }\end{array}$ & $\begin{array}{l}\text { Gras- } \\
\text { land. }\end{array}$ & Bonwlaud. & Graslaud. & $\begin{array}{l}\text { Bou wland en } \\
\text { grasl. samen. }\end{array}$ \\
\hline Drieglagstelsel & $\begin{array}{l}\text { Groningen } \\
\text { Friesland } \\
\text { Drente } \\
\text { Overijael } \\
\text { Gelderland } \\
\text { Utrecht } \\
\text { Noordholland } \\
\text { Noordbrabant } \\
\text { Limburg }\end{array}$ & $\begin{array}{r}530 \\
673 \\
529 \\
439 \\
605 \\
1050 \\
1109 \\
700 \\
725\end{array}$ & $\begin{array}{r}530 \\
701 \\
652 \\
617 \\
770 \\
1770 \\
1109 \\
730 \\
763\end{array}$ & $\begin{array}{r}16,300 \\
19,700 \\
34,000 \\
32,600 \\
69,800 \\
15,100 \\
2,000 \\
52,600 \\
42,500\end{array}$ & $\begin{array}{r}18,900 \\
73,700 \\
62,100 \\
55,500 \\
61,800 \\
15,900 \\
2,100 \\
37,100 \\
17,200\end{array}$ & $\begin{array}{r}8,639 \\
13,258 \\
17,986 \\
14,311 \\
42,229 \\
15,855 \\
2,218 \\
36,820 \\
30,812\end{array}$ & $\begin{array}{r}10,017 \\
51,664 \\
39,185 \\
34,244 \\
47,586 \\
28,143 \\
2,320 \\
27,083 \\
13,124\end{array}$ & $\begin{array}{r}18,656 \\
64,922 \\
57,171 \\
43,555 \\
89,815 \\
43,998 \\
4,538 \\
63,903 \\
43,936\end{array}$ \\
\hline Rijenteelt. & Groningen & 1288 & 1735 & 15,000 & 3,400 & 19,320 & 5,899 & 25,219 \\
\hline $\begin{array}{l}\text { Tweutsche } \\
\text { roggebouw. }\end{array}$ & Overijsel & 548 & 548 & 20,200 & 11,900 & 11,070 & 6,521 & 17,591 \\
\hline $\begin{array}{l}\text { Vlaamsche } \\
\text { bouwerij. }\end{array}$ & $\begin{array}{l}\text { Zeeland } \\
\text { Noordbrabant }\end{array}$ & $\begin{array}{l}1142 \\
1049\end{array}$ & $\begin{array}{l}1142 \\
1049\end{array}$ & $\begin{array}{r}5,500 \\
59,000\end{array}$ & $\begin{array}{r}500 \\
36,500\end{array}$ & $\begin{array}{r}6,281 \\
61,891\end{array}$ & $\begin{array}{r}571 \\
38,289\end{array}$ & $\begin{array}{r}6,852 \\
100,180\end{array}$ \\
\hline Goestboriwerij & $\begin{array}{l}\text { Noordholland } \\
\text { Zuidholland }\end{array}$ & $\begin{array}{l}2233 \\
1971\end{array}$ & $\begin{array}{l}2233 \\
2373\end{array}$ & $\begin{array}{l}2,900 \\
6,800\end{array}$ & $\begin{array}{l}15,200 \\
12,200\end{array}$ & $\begin{array}{r}6,476 \\
13,403\end{array}$ & $\begin{array}{l}34,164 \\
28,951\end{array}$ & $\begin{array}{l}40,640 \\
49,354\end{array}$ \\
\hline Veehouderij. & $\begin{array}{l}\text { Groningen } \\
\text { Frieslavd } \\
\text { Drente } \\
\text { Overijsel } \\
\text { Utrecht } \\
\text { NoordLolland } \\
\text { Zuidhulland } \\
\text { Noordbrabant }\end{array}$ & $\begin{array}{l}1340 \\
1840 \\
1808 \\
2165 \\
2208 \\
2116 \\
2111 \\
2190\end{array}$ & $\begin{array}{l}1600 \\
1840 \\
1808 \\
2165 \\
2208 \\
2116 \\
2299 \\
2190\end{array}$ & $\begin{array}{r}9,200 \\
4,300 \\
200 \\
3,000 \\
2,200 \\
10,300 \\
5,800 \\
1,900\end{array}$ & $\begin{array}{r}7,600 \\
96,600 \\
3,200 \\
35,600 \\
31,300 \\
85,000 \\
92,000 \\
12,400\end{array}$ & $\begin{array}{r}12,328 \\
7,912 \\
362 \\
6,495 \\
4,858 \\
21,795 \\
12,244 \\
4,161\end{array}$ & $\begin{array}{r}12,160 \\
177,744 \\
5,786 \\
77,074 \\
69,110 \\
179,860 \\
211,508 \\
27,156\end{array}$ & $\begin{array}{r}24,488 \\
185,656 \\
1,148 \\
83,569 \\
73,968 \\
201,655 \\
223,752 \\
31,317\end{array}$ \\
\hline Korenbouwerij & $\begin{array}{l}\text { Groningeu } \\
\text { Friesland } \\
\text { Overijsel } \\
\text { Gelderland } \\
\text { Noordholland } \\
\text { Zuidholland } \\
\text { Limburg }\end{array}$ & $\begin{array}{l}1350 \\
1588 \\
1118 \\
1464 \\
1711 \\
1460 \\
1710\end{array}$ & $\begin{array}{l}1540 \\
1580 \\
1118 \\
1676 \\
2315 \\
2169 \\
2172\end{array}$ & $\begin{array}{r}80,700 \\
27,800 \\
3,900 \\
20,100 \\
9,200 \\
9,400 \\
47,200\end{array}$ & $\mid \begin{array}{r}29,600 \\
28,500 \\
6,300 \\
23,900 \\
40,300 \\
23,500 \\
7,800\end{array}$ & $\begin{array}{r}108,945 \\
44,146 \\
4,360 \\
29,426 \\
15,741 \\
13,721 \\
80,712\end{array}$ & $\begin{array}{r}45,584 \\
45,030 \\
7,043 \\
40,056 \\
93,751 \\
50,972 \\
16,942\end{array}$ & $\begin{array}{r}154,529 \\
89,176 \\
11,403 \\
69,482 \\
109,492 \\
64,696 \\
97,654\end{array}$ \\
\hline Tarweteelt. & $\begin{array}{l}\text { Golderland } \\
\text { Utrecht } \\
\text { Zuidholland } \\
\text { Noordbrabant }\end{array}$ & $\begin{array}{l}1615 \\
1741 \\
2168 \\
1796\end{array}$ & $\begin{array}{l}2169 \\
1972 \\
2168 \\
2102\end{array}$ & $\begin{array}{r}36,700 \\
9,300 \\
1,400 \\
9,400\end{array}$ & $\begin{array}{r}55,400 \\
17,500 \\
5,800 \\
17,100\end{array}$ & $\begin{array}{r}59,271 \\
16,191 \\
3,035 \\
16,882\end{array}$ & $\begin{array}{r}120,380 \\
34,510 \\
12,574 \\
35,944\end{array}$ & $\begin{array}{r}179,651 \\
50,701 \\
15,609 \\
59,826\end{array}$ \\
\hline $\begin{array}{l}\text { Zoeuwache } \\
\text { tarweteelt. }\end{array}$ & $\begin{array}{l}\text { Zuidholland } \\
\text { Zeeland } \\
\text { Noordbrabant }\end{array}$ & $\begin{array}{l}1603 \\
1272 \\
1360\end{array}$ & $\begin{array}{l}1840 \\
1824 \\
1360\end{array}$ & $\begin{array}{l}43,500 \\
97,200 \\
22,300\end{array}$ & $\begin{array}{l}27,200 \\
36,500 \\
11,300\end{array}$ & $\begin{array}{r}69,731 \\
123,638 \\
30,328\end{array}$ & $\begin{array}{l}50,048 \\
51,976 \\
15,368\end{array}$ & $\begin{array}{r}119,779 \\
175,614 \\
45,696\end{array}$ \\
\hline Polderbouw. & $\begin{array}{l}\text { Utrecht } \\
\text { (Mijdrechi) } \\
\text { Noordholland }\end{array}$ & $\begin{array}{l}1415 \\
1035\end{array}$ & $\begin{array}{l}1415 \\
1035\end{array}$ & $\begin{array}{r}450 \\
13,200\end{array}$ & $\begin{array}{r}2.400 \\
11,100\end{array}$ & $\begin{array}{r}637 \\
13,662\end{array}$ & $\begin{array}{r}3,396 \\
11.489\end{array}$ & $\begin{array}{r}4,033 \\
25,151\end{array}$ \\
\hline
\end{tabular}


Het zal zeker de aandacht trekken, dat de koopwaarde der gronden in de provincie Groningen - die overigens bekend staat als een der vruchtbaarste gewesten - onder elk stelsel lager is, dan de overeenkomstige prijzen in bijna al de overige provincien. Het daar heerschende beklemrecht (het is hiervoren reeds opgemerkt) moet als oorzaak daarvoor worden aangewezen.

Met de berekeningen in tabel I rervat, mogen wij ons evenwel niet tevreden stellen.

Uit de gemiddelde prijzen van een bepaald stelsel, in de verschillende provincien gelegen, kan nog een voor het geheele stelsel als algemeen gemiddelde prijs gevonden worden, en dan komen wij tot de navolgende becijfering.

\begin{tabular}{|c|c|c|c|c|c|c|c|}
\hline \multirow{2}{*}{$\begin{array}{c}\text { II. } \\
\text { StejJskis IN } \\
\text { NEDERLLAND. }\end{array}$} & \multicolumn{2}{|c|}{$\begin{array}{l}\text { Genuiddelde } \\
\text { prijs per HA. } \\
\text { in guldens vonr }\end{array}$} & \multicolumn{2}{|c|}{$\begin{array}{l}\text { Aantal HA. cinder } \\
\text { elk stelsel gelegen. }\end{array}$} & \multicolumn{3}{|c|}{$\begin{array}{l}\text { Totaal waarde in duizend tallen } \\
\text { guldens van het onder elk } \\
\text { stelsel gelegen }\end{array}$} \\
\hline & $\begin{array}{l}\text { bouw- } \\
\text { land. }\end{array}$ & $\begin{array}{l}\text { gras- } \\
\text { land. }\end{array}$ & and. & d. & land. & d. & $\begin{array}{c}\text { himis } \\
\text { getisl. }\end{array}$ \\
\hline 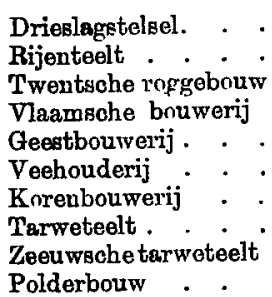 & $\begin{array}{r}707 \\
1988 \\
548 \\
1096 \\
2102 \\
1973 \\
1487 \\
1830 \\
1412 \\
1225\end{array}$ & $\begin{array}{r}850 \\
1735 \\
548 \\
1096 \\
2303 \\
2028 \\
1796 \\
2103 \\
1541 \\
1225\end{array}$ & $\begin{array}{r}284 \\
15 \\
20 \\
64 \\
9 \\
36 \\
198 \\
56 \\
163 \\
13\end{array}$ & $\begin{array}{r}3, \\
11, \\
37, \\
27, \\
363, \\
160, \\
95, \\
75, \\
13,\end{array}$ & $\begin{array}{l}212 \\
320 \\
770 \\
692 \\
389 \\
304 \\
792 \\
44 \\
56 \\
83\end{array}$ & $\begin{array}{r}292,655 \\
5,899 \\
6,521 \\
40,552 \\
63,109 \\
737,584 \\
287,360 \\
201,678 \\
115,575 \\
16,538\end{array}$ & $\begin{array}{r}493,867 \\
25,219 \\
17,591 \\
111,244 \\
\times 3,492 \\
810,387 \\
582,232 \\
305,622 \\
345,731 \\
33,320\end{array}$ \\
\hline Nederland & 1207 & 1564 & 862,700 & 1132,100 & 1041,242 & 1767,463 & 2808,705 \\
\hline
\end{tabular}

Naar de in tabel I gevolgde berekening vonden wij voor de verschillende stelsels de.navolgende waarden in tabel III opgenomen.

\begin{tabular}{|c|c|c|c|c|c|}
\hline \multirow{2}{*}{$\begin{array}{c}\text { III. } \\
\text { STELSRIS IN } \\
\text { NEDERIAAND. }\end{array}$} & \multicolumn{2}{|c|}{$\begin{array}{l}\text { Gemiddelde } \\
\text { prijs per BA. } \\
\text { in guldens }\end{array}$} & \multicolumn{3}{|c|}{$\begin{array}{c}\text { Totral waarde in guldens, ran het } \\
\text { onder elk stelsel gelegen }\end{array}$} \\
\hline & $\begin{array}{l}\text { bouw- } \\
\text { land. }\end{array}$ & $\underset{\text { land }}{\text { gra }}$ & land. & yrasland. & $\begin{array}{l}\text { bouw- en gras- } \\
\text { land samen. }\end{array}$ \\
\hline $\begin{array}{l}\text { Drieslagstelsel } \\
\text { Rijenteelt . } \\
\text { Twentsohe roggebouw } \\
\text { Vlanmsche buuwerij } \\
\text { Geestbouwerij } \\
\text { Veehouderij } \\
\text { Korenbouwerij }: \\
\text { Tarweteelt } \\
\text { Zeeuwsche tarweteolt } \\
\text { Poldesbouw }\end{array}$ & $\begin{array}{r}640 \\
1288 \\
548 \\
1057 \\
2049 \\
1900 \\
1498 \\
1679 \\
1372 \\
1044 \\
\end{array}$ & $\begin{array}{r}736 \\
1735 \\
548 \\
1057 \\
2303 \\
2091 \\
1870 \\
2121 \\
1565 \\
1103 \\
\end{array}$ & $\begin{array}{r}182,128,000 \\
19,320,000 \\
11,070,000 \\
68,172,000 \\
19,879,000 \\
70,155,000 \\
297,054,000 \\
95,379,000 \\
223,697,000 \\
14,299,000 \\
\end{array}$ & $\begin{array}{r}253,366,000 \\
5,899,000 \\
6,521,000 \\
38,860,000 \\
63,115,000 \\
760,399,000 \\
299,378,000 \\
203,408,000 \\
117,392,000 \\
14,885,000 \\
\end{array}$ & $\begin{array}{r}435,494,000 \\
25,219,000 \\
17,591,000 \\
107,032,000 \\
82,995,000 \\
830,553,000 \\
596,439,000 \\
298,787,000 \\
341,089,000 \\
29,184,000 \\
\end{array}$ \\
\hline Nederland & 1160 & 1557 & $1004,153,000$ & $1763,222,000$ & $2764,375,000$ \\
\hline
\end{tabular}


$\mathrm{Nu}$ is het mogelijk uit de tabellen II en III nog gemiddelden te zoeken, waardoor wij der waarheid weder meer nabij komen. Wij zullen dan tevens die tabel zoodanig inrichten dat wij tevens een overzicht verkrijgen van de koopwaarde der zand- en kleigronden. De stelsels Geestbouwerij, waarbij door sterke bemesting en bijzondere cultures een zeer hooge waarde aan den bodem gegeven is, zullen wij afzonderlijk behouden, zoomede het stelsel Rijenteelt op afgeveende hooge veengronden, en het stelsel Vlaamsche-bouwerij waarbij door het teelen van groen voeder de veestapel in verhouding tot het bouwland zeer groot is, en dus ook een ruimere bemesting wordt toegepast.

In tabel IV hebben wij deze berekening te zamen gevat.

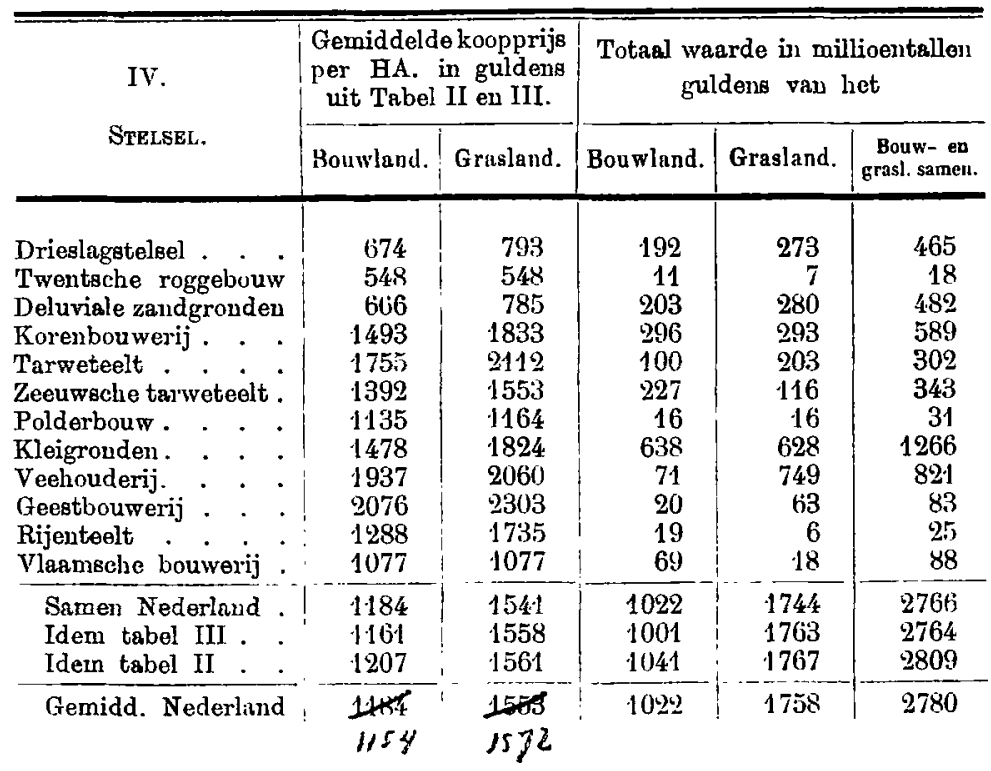

Hebben wịj tot hiertoe de gemiddelde prijzen berekend van de gronden onder de verschillende landbouwstelsels gelegen, ons rest thans nog, die te berekenen naar de verschillende provinciën.

Ook hiervoor kumnen wị meer dan één weg inslaan, doch bepalen ons er toe, de som te nemen van de waarde der grouden onler die landbouwstelsels, waaruit elke provincie bestaat en die wij in tabel I hebben opgenomen. Wị komen dan tot de cijfers in tabel $\mathrm{V}$ vermeld. 


\begin{tabular}{|c|c|c|c|c|c|c|c|c|}
\hline \multirow[t]{2}{*}{$\begin{array}{c}\text { V. } \\
\text { PROVINCIEN. }\end{array}$} & & \multicolumn{2}{|c|}{$\begin{array}{l}\text { Gemiddelde } \\
\text { prijs per HA. } \\
\text { in guldens, } \\
\text { voor het }\end{array}$} & \multicolumn{2}{|c|}{$\begin{array}{l}\text { Aantal HA. in } \\
\text { olke provinoie } \\
\text { aanwezig. }\end{array}$} & \multicolumn{3}{|c|}{$\begin{array}{c}\text { Totaal waarde in } \\
\text { milioentallen guldens } \\
\text { van het }\end{array}$} \\
\hline & & $\begin{array}{l}\text { bonw- } \\
\text { land. }\end{array}$ & $\begin{array}{l}\text { gras- } \\
\text { land. }\end{array}$ & bonwland. & grasland. & bouwland. & grasland. & $\begin{array}{l}\text { bouw- en } \\
\text { grasl. samen. }\end{array}$ \\
\hline $\begin{array}{l}\text { Groningen : } \\
\text { Friesland : } \\
\text { Drente } \\
\text { Overijsel : } \\
\text { Gelderland : } \\
\text { Utrecht. } \\
\text { Noord-Holland } \\
\text { Zuid-Holland . } \\
\text { Zeoland . } \\
\text { Noord-Brabaut } \\
\text { Limburg . . }\end{array}$ & & $\begin{array}{r}1231 \\
1261 \\
536 \\
607 \\
1034 \\
1385 \\
1593 \\
1676 \\
1265 \\
1034 \\
1243\end{array}$ & $\begin{array}{r}1238 \\
1380 \\
689 \\
1143 \\
1473 \\
2002 \\
2092 \\
2203 \\
1420 \\
1257 \\
1203\end{array}$ & $\begin{array}{r}121,200 \\
51,800 \\
34,200 \\
59,700 \\
126,600 \\
27,100 \\
37,600 \\
66,900 \\
102,700 \\
145,200 \\
89,700\end{array}$ & $\begin{array}{r}59,500 \\
198,800 \\
65,300 \\
109,300 \\
141,200 \\
67,100 \\
153,700 \\
160,700 \\
37,000 \\
114,400 \\
25,000\end{array}$ & $\begin{array}{r}149 \\
65 \\
18 \\
36 \\
131 \\
38 \\
60 \\
112 \\
130 \\
150 \\
112\end{array}$ & $\begin{array}{r}74 \\
274 \\
45 \\
125 \\
208 \\
135 \\
322 \\
354 \\
53 \\
144 \\
30\end{array}$ & $\begin{array}{r}223 \\
340 \\
63 \\
161 \\
339 \\
173 \\
381 \\
466 \\
182 \\
294 \\
142\end{array}$ \\
\hline $\begin{array}{r}\text { Nederlend . } \\
\qquad W .\end{array}$ & & 1160 & 1558 & 862,700 & $1,132,000$ & 1001 & 1763 & 2764 \\
\hline
\end{tabular}

Naschrift. Het zoude niet onbelangrijk zijn, deze berekening van de kapitaalwaarde der bouw- en graslanden te vergelijken met hunne belastbare opbrengst volgens het kadaster. Dat is echter voorshands niet doenlijk, dewijl aanwijzingen hoe die kadastrale opbrengst zich over de verschillende soorten der ongeb. eigendommen verdeelt, ontbreken. Trouwens, van de menigvuldige veranderingen in de soort van kultuur wordt bij het kadaster slechts aanteekening gehouden bij nieuwe meting van perceelen. Zoowel om die reden, als wegens het thans verordende schattingeijfer, zal men voor dergelijke vergelijking, de uitkomsten der thans loopende herziening dienen af te wachten.

RED. 